\title{
EVALUASI KEBUTUHAN AIR DAN ELEVASI BUKAAN PINTU PADA SISTEM TATA AIR PASANG SURUT UNIT TAMBAN KABUPATEN BARITO KUALA
}

\author{
Febry Asthia Miranti ${ }^{1}$ \\ ${ }^{1}$ Balai Wilayah Sungai Kalimantan II
}

\begin{abstract}
ABSTRAK
Upaya rehabilitasi dilakukan terhadap sistem tata air pasang surut DIR Unit Tamban di Desa Tamban Sari Bangun kabupaten Barito Kuala pada tahun 2013, diantaranya dengan memasang Pintu Klep berdimensi $600 \mathrm{~cm} \times 400 \mathrm{~cm}$ agar produktivitas lahan yang telah terdegradasi dapat ditingkatkan. Namun, pintu klep tersebut tidak difungsikan dan dioperasionalkan oleh petani setempat, sehingga diperlukan evaluasi kebutuhan air, dan evaluasi bukaan pintu klep. Pada penelitian ini dilakukan analisis curah hujan andalan, analisis evapotranspirasi, analisis kebutuhan air irigasi, analisis pasang surut, evaluasi tata air eksisting, dan simulasi menggunakan program HEC-RAS. Tahap akhir penelitian didapatkan kesimpulan dan saranmengenai evaluasi kebutuhan air dan elevasi bukaan pintu pada sistem tata air Unit Tamban. Berdasarkan hasil perhitungan kebutuhan irigasi, diketahui elevasi muka air tertinggi untuk pengolahan tanah ada di Juni I yaitu +9,040m, sedangkan masa pertumbuhan di Agustus I yaitu +9.060m. Dari hasil simulasi hec-ras diketahui bahwa pemenuhan air di sawahl (hulu) tidak dapat tercukupi, dikarenakan elevasi sawah terlalu tinggi. Sedangkan pemenuhan kebutuhan air di sawah2 (hilir) dapat tercukupi di simulasi 10, dengan kondisi elevasi dasar pintu air eksisting , pintu air dibuka penuh, dan hidrograf pasang surut dinaikkan 1,03 kali. Pemenuhan kebutuhan air terpenuhi jika pasang surut lebih tinggi dari hasil pengukuran yaitu 1,03 kali.
\end{abstract}

Kata Kunci: rawa pasang surut, irigasi rawa tamban, kebutuhan air irigasi, HEC-RAS.

\section{PENDAHULUAN}

Kalimantan Selatan memiliki \pm 1 juta ha lahan rawa yang secara parsial tersebar di beberapa Kabupaten di Kalimantan Selatan dan hanya sekitar 0,45 juta ha saja yang baru dimanfaatkan termasuk sebagai lahan areal pertanian. Unit Tamban Kabupaten Barito Kuala merupakan salah satu dari 18 (delapan belas) unit pengembangan rawa pasang surut dan non pasang surut di Kabupaten Barito Kuala yang pengembangannya telah dilakukan sejak tahun 1970. Pemanfaatan lahan rawa dihadapkan pada suatu permasalahan di mana lahan rawa merupakan lahan yang mempunyai potensi rendah sampai sangat rendah untuk menghasilkan tanaman pertanian. Kunci keberhasilan dalam pengembangan rawa agar dapat dimanfaatkan dengan baik adalah teknik pengolahan tanah dan tata air yang tepat.

Telah dilakukan beberapa upaya rehabilitasi terhadap sistem tata air pasang surut Daerah Irigasi Rawa Unit Tamban di Desa

Correspondence: Febry Asthia Miranti

Email : asthiamiranti@gmail.com
Tamban Sari Bangun pada tahun 2013, salah satunya dengan memasang Pintu Klep berbahan dasar fiber dengan dimensi $600 \mathrm{~cm} \mathrm{x}$ $400 \mathrm{~cm}$. Hal ini dilakukan dalam rangka meningkatkan kembali produktivitas lahan yang sebelumnya telah mengalami degradasi. Namun dalam pelaksanaannya, pintu klep tersebut tidak difungsikan dan dioperasionalkan sesuai dengan perencanaan oleh petani setempat sehingga tujuan pelaksanaan rehabilitasi tidak tercapai. Dengan demikian diperlukan evaluasi terhadap sistem tata air pasang surut Unit Tamban dengan mengevaluasi kebutuhan air, dan bukaan pintu klep di lokus penelitian yang bertujuan untuk mengetahui kondisi eksisting pola tata air, jumlah kebutuhan air di sawah, dan besarnya bukaan pintu klep di Tamban Sari Bangun.

Dari latar belakang permasalahan tersebut, sangat diperlukan suatu penelitian yang mampu mengetahui jumlah kebutuhan air dan besar bukaan pintu klep di Desa Tamban Sari Bangun. Batasan masalah dalam penelitian ini adalah Lokasi penelitian di daerah pasang-surut Unit Tamban Desa Tamban Sari Bangun, Kabupaten Barito Kuala, Provinsi Kalimantan 
Selatan; Simulasi sistem tata air makro Unit Tamban dilakukan di Saluran Tamban Sari Bangun, Desa Tamban Sari Bangun dengan menggunakan program Hec-Ras; Pintu klep yang digunakan berbahan dasar fiber glass,; Simulasi dilakukan dengan menggunakan data elevasi muka air tanggal 2 oktober 2017 pukul 10.00 wita hingga 3 oktober 2017 pukul 14.00 wita.

\section{METODE PENELITIAN}

Penelitian ini dilaksanakan dalam lima tahap yaitu studi pustaka; pengumpulan data sekunder; pengumpulan data primer; identifikasi pola tata air; dan analisis perhitungan dan kesimpulan. Studi Pustaka dilakukan dengan mengumpulkan dan mengkaji data-data dan infomasi dari makalah, laporan, gambar desain, jurnal, dan buku yang berhubungan dengan penelitian ini, di antaranya mengenai lahan rawa pasang surut, hidrometri saluran, dan pemodelan menggunakan program Hec-Ras. Data sekunder diperoleh dari institusi yang berwenang mengeluarkan data tersebut dari instansi pemerintah maupun lembaga terkait lainnya. Data sekunder yang diperlukan adalah peta situasi, data curah hujan, data klimatologi, dan data luas areal pertanian. Data primer diperoleh dari hasil survey, pengamatan langsung, dan pengukuran langsung di lapangan. Data primer yang diperoleh adalah pengukuran dimensi saluran, pengamatan tinggi muka air, dan pengukuran kecepatan.

Analisis data yang diperlukan dalam penelitian ini adalah Analisis Curah Hujan Andalan, Analisis Evapotranspirasi, Analisis Kebutuhan Air Irigasi, Analisis Pasang Surut, Evaluasi Tata Air Eksisting, Simulasi dengan menggunakan Program HEC-RAS.Tahap akhir dari penelitian ini didapatkan suatu kesimpulan dan saran mengenai evaluasi kebutuhan air dan elevasi bukaan pintu pada sistem tata air pasang surut Unit Tamban Kabupaten Barito Kuala.

\section{HASIL DAN PEMBAHASAN}

\subsection{Analisis Curah Hujan Andalan}

Hujan rata-rata kawasan di Daerah Irigasi Rawa Unit Tamban merupakan rata-rata hujan dari stasiun Marabahan, stasiun Sungai Tabuk, dan stasiun Binuang. Data ini kemudian digunakan dalam perhitungan curah hujan dengan kemungkinan terpenuhi $80 \%$ dari pendekatan distribusi normal. Contoh perhitungan curah hujan probabilitas $80 \%$ pada bulan Januari tahun 1990-Desember 2005 terlihat pada Tabel 1.

Tabel 1. Data rata-rata hujan kawasan di Daerah Irigasi Rawa Unit Tamban pada bulan Januari tahun 1990 - 2005.

\begin{tabular}{cccc}
\hline Bulan & Curah Hujan (mm/bln) & Bulan & Curah Hujan $(\mathbf{m m} / \mathbf{b l n})$ \\
\hline Jan 1990 & 1026 & Jan 1998 & 123 \\
Jan 1991 & 517 & Jan 1999 & 377 \\
Jan 1992 & 253 & Jan 2000 & 76 \\
Jan 1993 & 198 & Jan 2001 & 391 \\
Jan 1994 & 313 & Jan 2002 & 221 \\
Jan 1995 & 435 & Jan 2003 & 172 \\
Jan 1996 & 435 & Jan 2004 & 329 \\
Jan 1997 & 78 & Jan 2005 & 204 \\
\hline
\end{tabular}

Sumber: Hasil Perhitungan

$$
\text { - Hujan rata-rata }=\frac{\sum P}{x}
$$

Di mana $P$ adalah curah hujan, $x$ adalah jumlah data, sehingga :

$$
\begin{aligned}
& =\frac{5.147}{16} \\
& =321,71 \mathrm{~mm}
\end{aligned}
$$

$$
\begin{aligned}
& \text { - Standart deviasi }(S d) \quad=143,32 \mathrm{~mm} \\
& \text { Besarnya hujan andalan }\left(\mathrm{R}_{80}\right) \\
& \quad=\mathrm{P}_{\text {rata-rata }}-\mathrm{K}_{\mathrm{f}} . S d \\
& \quad=321,71-0.842 \times 143,32 \\
& \quad=201,04 \mathrm{~mm} / \mathrm{bln} \\
& \quad=6,49 \mathrm{~mm} / \mathrm{hari}
\end{aligned}
$$




\subsection{Analisis Evapotranspirasi}

Nilai evapotranspirasi dapat diketahui dari perhitungan dengan menggunakan Metode Penman. Perhitungan dengan menggunakan Metode Penman dilakukan dengan memasukkan parameter pencatatan klimatologi di Stasiun Klimatologi Sungai Tabuk yang berada pada $02^{\circ} 57^{\prime} \mathrm{LS}$ dan $115^{\circ} 9^{\prime}$ BT dengan ketinggian $+5,00 \mathrm{~m}$. Data klimatologi yang digunakan meliputi data kelembaban udara, kecepatan angin, lama peyinaran matahari, dan suhu udara. Hasil perhitungan evapotranspirasi kemudian digunakan dalam analisis kebutuhan air irigasi.

$$
\begin{aligned}
& \text { - Evapotranspirasi sebenarnya (ET*), } \\
& =\mathrm{w}(0,75 \mathrm{Rs}-\mathrm{Rn} 1)+(1-\mathrm{w}) \mathrm{f}(\mathrm{u})(\mathrm{ea}-\mathrm{ed}) \\
& =0,76(0,75 \cdot 8,17-0,81)+(1-0,76) \cdot 0,38 \cdot 2,12 \\
& =4,25 \mathrm{~mm} / \text { hari } \\
& \text { - Angka koreksi Penman (c) } \quad=1,10 \\
& \text { - Evapotranspirasi Potensial harian (ETo*), } \\
& \begin{array}{l}
=\mathrm{c} \mathrm{ET} * \\
=1,10 \times 4,25 \\
=4,68 \mathrm{~mm} / \mathrm{hari}
\end{array}
\end{aligned}
$$

\subsection{Analisis Kebutuhan Air Irigasi}

Perhitungan kebutuhan air irigasi dilakukan dengan menjumlahkan besarnya air yang dibutuhkan di sawah (penguapan, peresapan, penjenuhan tanah, dan penggenangan) dan kehilangan selama penyaluran. Besarnya satuan kebutuhan air di sawah dihitung dengan satuan kebutuhan air setiap satuan luas. Contoh perhitungan kebutuhan air irigasi di Daerah Irigasi Rawa Unit Tamban selengkapnya sebagai berikut:

1. Evapotranspirasi potensial (Eto)

Hasil perhitungan evapotranspirasi sesuai dengan hasil analisis evapotranspirasi di daerah Irigasi sebelumnya.

2. Hujan R80 dan curah hujan efektif

a. Hujan $\mathrm{R}_{80}$

Hasil perhitungan hujan andalan sesuai dengan hasil analisis evapotranspirasi di Daerah Irigasi Rawa Unit Tamban sebelumnya.

b. Curah hujan efektif

Hasil perhitungan hujan efektif tanaman padi dan palawija di Daerah Irigasi Rawa Unit Tamban dapat dilihat dalam Tabel 2.

Dari Tabel 2 dapat diketahui besaranya curah hujan yang dapat diserap oleh tanaman.

\begin{tabular}{|c|c|c|c|c|c|c|c|c|c|c|c|c|c|}
\hline Tanaman & 2 minggu ke- & Jan & Feb & Mar & Apr & Mei & Jun & Jul & Agt & Sep & Okt & Nop & Des \\
\hline \multirow{9}{*}{ Padi } & 1 & 0.78 & 0.72 & 0.67 & 0.64 & 0.58 & 0.14 & 0.11 & 0.16 & 0.14 & 0.42 & 0.71 & 1.15 \\
\hline & 2 & 2.27 & 2.11 & 1.94 & 1.87 & 1.69 & 0.41 & 0.31 & 0.46 & 0.41 & 1.23 & 2.07 & 3.36 \\
\hline & 3 & 3.11 & 2.89 & 2.66 & 2.56 & 2.31 & 0.57 & 0.43 & 0.63 & 0.57 & 1.69 & 2.84 & 4.61 \\
\hline & 4 & 3.24 & 3.01 & 2.77 & 2.67 & 2.41 & 0.59 & 0.45 & 0.66 & 0.59 & 1.76 & 2.95 & 4.80 \\
\hline & 5 & 2.59 & 2.41 & 2.22 & 2.14 & 1.93 & 0.47 & 0.36 & 0.53 & 0.47 & 1.41 & 2.36 & 3.84 \\
\hline & 6 & 2.59 & 2.41 & 2.22 & 2.14 & 1.93 & 0.47 & 0.36 & 0.53 & 0.47 & 1.41 & 2.36 & 3.84 \\
\hline & 7 & 2.59 & 2.41 & 2.22 & 2.14 & 1.93 & 0.47 & 0.36 & 0.53 & 0.47 & 1.41 & 2.36 & 3.84 \\
\hline & 8 & 1.75 & 1.63 & 1.50 & 1.44 & 1.30 & 0.32 & 0.24 & 0.35 & 0.32 & 0.95 & 1.60 & 2.59 \\
\hline & 9 & 0.84 & 0.78 & 0.72 & 0.69 & 0.63 & 0.15 & 0.12 & 0.17 & 0.15 & 0.46 & 0.77 & 1.25 \\
\hline Palawija & & 4.79 & 4.48 & 3.74 & 3.47 & 3.29 & 0.89 & 0.70 & 1.08 & 1.01 & 1.20 & 2.92 & 3.83 \\
\hline
\end{tabular}
Tanaman dapat menyerap air pada bulan-bulan basah, sedangkan pada musim kemarau tanaman cenderung kekurangan air. Hal ini dikarenakan hujan pada musim kemarau relatif sedikit.

Tabel 2. Curah hujan efektif (mm/hari).

\subsection{Kebutuhan air untuk penyiapan lahan}

Penyiapan lahan untuk padi dilakukan selama 30 hari dengan angka penjenuhan tanah sebesar $200 \mathrm{~mm}$, sedangkan untuk palawija selama 15 hari dengan angka penjenuhan tanah sebesar $50 \mathrm{~mm}$. Berdasarkan pola tanam di
Daerah Rawa Unit Tamban maka penyiapan lahan untuk padi pada MT I dimulai dari tanggal 01 November hingga 30 November, MT II dimulai dari tanggal 01 Maret hingga 31 Maret, sedangkan untuk penyiapan lahan untuk palawija pada MT III dari tanggal 01 Juli 
hingga 15 Juli. Hasil perhitungan kebutuhan air untuk penyiapan lahan untuk palawija dan padi di Daerah Irigasi Rawa Unit Tamban selengkapnya dapat dilihat pada Tabel 3.

Tabel 3. Kebutuhan air untuk penyiapan lahan ( $\mathrm{mm} / \mathrm{hari})$.

\begin{tabular}{ccc}
\hline Bulan & Padi & Palawija \\
\hline Jan & 12,70 & 8,48 \\
Feb & 12,80 & 8,65 \\
Mar & 12,35 & 8,10 \\
Apr & 11,80 & 7,37 \\
Mei & 12,30 & 7,99 \\
Jun & 11,37 & 6,86 \\
Jul & 12,00 & 7,59 \\
Agt & 12,78 & 8,62 \\
Sep & 13,21 & 9,23 \\
Okt & 12,88 & 8,78 \\
Nov & 12,21 & 7,90 \\
Des & 12,56 & 8,35 \\
\hline
\end{tabular}

Tabel 3 menunjukkan variasi kebutuhan air untuk penyiapan lahan. Kebutuhan air terbesar ada pada bulan September dengan ketinggian air 13,21 $\mathrm{mm}$ /hari untuk tanaman padi dan 9,23 $\mathrm{mm} /$ hari untuk tanaman palawija, sedangkan kebutuhan air terkecil ada pada bulan Juni sebesar $11,37 \mathrm{~mm} /$ hari untuk tanaman padi dan $6,86 \mathrm{~mm} /$ hari untuk tanaman palawija. Penyiapan lahan untuk Masa Tanam 1 diperlukan air sebesar 12,30 mm/hari.

\subsection{Kebutuhan konsumtif tanaman (Etc)}

Kebutuhan konsumtif tanaman merupakan kebutuhan tanaman untuk berevapotranspirasi yang dipengaruhi oleh faktor jenis tanaman, umur tanaman, dan klimatologi. Hasil perhitungan kebutuhan konsumtif tanaman untuk palawija dan padi di Daerah Irigasi Rawa Unit Tamban selengkapnya dapat dilihat pada Tabel 4.

Tabel 4. Penggunaan konsumtif tanaman (mm/hari).

\begin{tabular}{cccccccccccccc}
\hline Tanaman & $\begin{array}{c}\text { 2 minggu } \\
\text { ke- }\end{array}$ & Jan & Feb & Mar & Apr & Mei & Jun & Jul & Agt & Sep & Okt & Nop & Des \\
\hline \multirow{6}{*}{ Padi } & 1 & 6.74 & 6.98 & 6.18 & 5.08 & 6.01 & 4.28 & 5.42 & 6.94 & 7.82 & 7.17 & 5.89 & 6.55 \\
& 2 & 7.13 & 7.39 & 6.54 & 5.38 & 6.36 & 4.53 & 5.74 & 7.34 & 8.27 & 7.59 & 6.23 & 6.93 \\
& 3 & 7.47 & 7.74 & 6.85 & 5.63 & 6.66 & 4.75 & 6.01 & 7.69 & 8.66 & 7.95 & 6.53 & 7.26 \\
& 4 & 7.30 & 7.56 & 6.70 & 5.50 & 6.51 & 4.64 & 5.87 & 7.52 & 8.47 & 7.77 & 6.38 & 7.10 \\
& 5 & 6.46 & 6.69 & 5.92 & 4.87 & 5.76 & 4.11 & 5.20 & 6.65 & 7.49 & 6.87 & 5.64 & 6.28 \\
& 6 & 0.00 & 0.00 & 0.00 & 0.00 & 0.00 & 0.00 & 0.00 & 0.00 & 0.00 & 0.00 & 0.00 & 0.00 \\
\hline \multirow{5}{*}{ Palawija } & rata2 & 5.85 & 6.06 & 5.37 & 4.41 & 5.22 & 3.72 & 4.71 & 6.02 & 6.78 & 6.22 & 5.11 & 5.69 \\
\hline & 1 & 3.23 & 3.35 & 2.96 & 2.43 & 2.88 & 2.05 & 2.60 & 3.32 & 3.75 & 3.44 & 2.82 & 3.14 \\
& 2 & 3.81 & 3.95 & 3.50 & 2.87 & 3.40 & 2.42 & 3.07 & 3.92 & 4.42 & 4.05 & 3.33 & 3.70 \\
& 3 & 6.20 & 6.42 & 5.69 & 4.67 & 5.53 & 3.94 & 4.99 & 6.38 & 7.19 & 6.60 & 5.42 & 6.03 \\
& 4 & 6.78 & 7.03 & 6.22 & 5.11 & 6.05 & 4.31 & 5.46 & 6.98 & 7.86 & 7.21 & 5.92 & 6.59 \\
& 5 & 6.58 & 6.83 & 6.04 & 4.97 & 5.88 & 4.19 & 5.30 & 6.78 & 7.64 & 7.01 & 5.76 & 6.41 \\
& 6 & 6.13 & 6.36 & 5.63 & 4.62 & 5.47 & 3.90 & 4.94 & 6.32 & 7.12 & 6.53 & 5.36 & 5.97 \\
\hline
\end{tabular}

Dari Tabel 4. dapat dilihat bahwa kebutuhan terbesar terjadi pada bulan September sebesar 6,78 $\mathrm{mm} /$ hari untuk tanaman padi dan $6,33 \mathrm{~mm} /$ hari untuk palawija. Besarnya kebutuhan air untuk pertumbuhan tanaman ini dikarenakan angka evapotransiprasi yang terjadi pada bulan September relatif tinggi sehingga tanaman butuh asupan air yang banyak untuk bisa tumbuh. Sedangkan kebutuhan penggunaan konsumtif tanaman relatif kecil pada bulan- bulan basah, bulan dengan angka evapotranspirasi rendah.

\subsection{Kebutuhan air pada petak sawah}

Besarnya kebutuhan air disawah tergantung dari pola tanam yang ditetapkan dan luas areal. Luas areal irigasi rawa Unit Tamban Desa Tamban Sari Bangun secara keseluruhan adalah 350 ha. Hasil perhitungan kebutuhan air di Daerah Irigasi Rawa Unit Tamban disajikan dalam Tabel 5. 
Febry Asthia Miranti

Dari Tabel 5. diketahui bahwa kebutuhan air rata - rata di sawah terbesar ada pada bulan Agustus, hal ini dikarenakan pada bulan tersebut telah memasuki musim kemarau, sehingga supply air untuk pertumbuhan tanaman padi tidak tercukupi oleh curah hujan sedangkan jumlah penguapan besar.

Tabel 5. Kebutuhan air di sawah (lt/dt/ha).

\begin{tabular}{ccc}
\hline Masa Tanam & Bulan & Kebutuhan Air \\
& Mei II & 0.68 \\
& Jun I & 1.29 \\
& Jun II & 1.16 \\
MT I & Jul I & 1.21 \\
& Jul II & 1.25 \\
& Agt I & 1.44 \\
& Agt II & 1.19 \\
& Sep I & 0.62 \\
& Sep II & 0.10 \\
\hline
\end{tabular}

\subsection{Analisis Pasang Surut}

Analisis pasang surut dimaksudkan untuk mengetahui elevasi pasang tertinggi dan elevasi surut terendah yang terjadi di Saluran Sekunder dan Saluran Tersier Desa Tamban Sari Bangun. Analisis pasang surut dilakukan terhadap data elevasi muka air hasil pencatatan pengamatan elevasi muka air. Pengamatan pasang surut dilakukan dengan memasang papan duga air (peil scale) di 5 (lima) titik, yaitu di bagian hulu saluran sekunder, hilir saluran sekunder, hulu saluran tersier, tengah saluran tersier, dan hilir saluran tersier di Desa Tamban Sari Bangun.

Pengamatan muka air dilakukan selama 29 jam pada tanggal 2 Oktober 2017 hingga 3 oktober 2017. Pengamatan pasang surut dilakukan dengan melakukan pencatatan elevasi muka air tiap jam. Hasil pengamatan pasang surut di 5 (lima) titik di Saluran Sekunder dan Tersier Desa Tamban Sari Bangun selengkapnya disajikan dalam Tabel 6.

Tabel 6 menunjukkan variasi elevasi muka air pasang dan surut di saluran sekunder dan tersier. Elevasi muka air pasang tertinggi terjadi pada tanggal 3 Oktober 2017 tepatnya pada pukul 6.00 am, sedangkan elevasi muka air surut terendah terjadi pada tanggal 2 Oktober 2017 tepatnya pada pukul 11.00 pm. Fluktuasi pasang dan surut tertinggi terjadi di saluran sekunder hilir, dengan elevasi pasang tertinggi sebesar $+9,00 \mathrm{~m}$ dan elevasi surut terendah sebesar $+7,50 \mathrm{~m}$. Fluktuasi pasang dan surut terendah terjadi di saluran tersier hilir, dengan elevasi pasang tertinggi sebesar $+8,94 \mathrm{~m}$ dan elevasi surut terendah sebesar $\quad+8,74 \mathrm{~m}$.

Tabel 6. Pengamatan tinggi muka air (m).

\begin{tabular}{ccccccccc}
\hline No & Hari/Tanggal & Waktu & $\begin{array}{c}\text { Sekunder } \\
\text { Hilir }\end{array}$ & $\begin{array}{c}\text { Sekunder } \\
\text { Hulu }\end{array}$ & $\begin{array}{c}\text { Tersier } \\
\text { Hilir }\end{array}$ & $\begin{array}{c}\text { Tersier } \\
\text { Tengah }\end{array}$ & $\begin{array}{c}\text { Tersier } \\
\text { Hilir }\end{array}$ & Ket \\
\hline 1 & Senin, 2 Okt 2017 & 10:00 AM & 8.50 & 8.529 & 8.76 & 8.35 & 8.34 & Surut \\
2 & Senin, 2 Okt 2017 & $11: 00$ AM & 8.40 & 8.45 & 8.75 & 8.26 & 8.34 & Surut \\
3 & Senin, 2 Okt 2017 & 12:00 PM & 8.30 & 8.38 & 8.75 & 8.17 & 8.34 & Surut \\
4 & Senin, 2 Okt 2017 & $1: 00$ PM & 8.18 & 8.30 & 8.74 & 8.11 & 8.33 & Surut \\
5 & Senin, 2 Okt 2017 & $2: 00$ PM & 8.28 & 8.28 & 8.74 & 8.11 & 8.33 & Surut \\
6 & Senin, 2 Okt 2017 & 3:00 PM & 8.30 & 8.27 & 8.74 & 8.12 & 8.32 & Surut \\
7 & Senin, 2 Okt 2017 & $4: 00$ PM & 8.20 & 8.15 & 8.74 & 8.01 & 8.31 & Surut \\
8 & Senin, 2 Okt 2017 & $5: 00$ PM & 8.05 & 8.03 & 8.74 & 7.90 & 8.31 & Surut \\
9 & Senin, 2 Okt 2017 & 6:00 PM & 7.92 & 7.92 & 8.74 & 7.86 & 8.30 & Surut \\
10 & Senin, 2 Okt 2017 & $7: 00$ PM & 7.76 & 7.81 & 8.74 & 7.85 & 8.29 & Surut \\
11 & Senin, 2 Okt 2017 & $8: 00$ PM & 7.64 & 7.76 & 8.74 & 7.85 & 8.29 & Surut \\
12 & Senin, 2 Okt 2017 & $9: 00$ PM & 7.56 & 7.74 & 8.74 & 7.85 & 8.29 & Surut \\
13 & Senin, 2 Okt 2017 & 10:00 PM & 7.54 & 7.73 & 8.74 & 7.85 & 8.29 & Surut \\
\hline
\end{tabular}

(dilanjutkan) 
Tabel 6 (lanjutan)

\begin{tabular}{rrrrrrrrr}
\hline No & Hari/Tanggal & Waktu & $\begin{array}{c}\text { Sekunder } \\
\text { Hilir }\end{array}$ & $\begin{array}{c}\text { Sekunder } \\
\text { Hulu }\end{array}$ & $\begin{array}{c}\text { Tersier } \\
\text { Hilir }\end{array}$ & $\begin{array}{c}\text { Tersier } \\
\text { Tengah }\end{array}$ & $\begin{array}{c}\text { Tersier } \\
\text { Hilir }\end{array}$ & Ket \\
\hline 15 & Selasa, 3 Okt 2017 & 12:00 AM & 7.90 & 7.93 & 8.74 & 7.85 & 8.29 & Pasang \\
16 & Selasa, 3 Okt 2017 & 1:00 AM & 8.40 & 8.41 & 8.74 & 8.18 & 8.29 & Pasang \\
17 & Selasa, 3 Okt 2017 & 2:00 AM & 8.67 & 8.65 & 8.74 & 8.49 & 8.33 & Pasang \\
18 & Selasa, 3 Okt 2017 & 3:00 AM & 8.86 & 8.80 & 8.84 & 8.65 & 8.50 & Pasang \\
19 & Selasa, 3 Okt 2017 & 4:00 AM & 8.95 & 8.82 & 8.89 & 8.73 & 8.53 & Pasang \\
20 & Selasa, 3 Okt 2017 & 5:00 AM & 8.97 & 8.83 & 8.92 & 8.75 & 8.55 & Pasang \\
21 & Selasa, 3 Okt 2017 & 6:00 AM & 9.00 & 8.88 & 8.94 & 8.76 & 8.55 & Pasang \\
22 & Selasa, 3 Okt 2017 & 7:00 AM & 8.95 & 8.89 & 8.93 & 8.75 & 8.59 & Surut \\
23 & Selasa, 3 Okt 2017 & 8:00 AM & 8.88 & 8.83 & 8.83 & 8.70 & 8.55 & Surut \\
24 & Selasa, 3 Okt 2017 & 9:00 AM & 8.78 & 8.81 & 8.78 & 8.64 & 8.52 & Surut \\
25 & Selasa, 3 Okt 2017 & 10:00 AM & 8.62 & 8.71 & 8.76 & 8.51 & 8.43 & Surut \\
26 & Selasa, 3 Okt 2017 & $11: 00 \mathrm{AM}$ & 8.52 & 8.63 & 8.75 & 8.42 & 8.39 & Surut \\
27 & Selasa, 3 Okt 2017 & 12:00 PM & 8.40 & 8.53 & 8.74 & 8.30 & 8.34 & Surut \\
28 & Selasa, 3 Okt 2017 & 1:00 PM & 8.38 & 8.42 & 8.74 & 8.24 & 8.34 & Surut \\
29 & Selasa, 3 Okt 2017 & 2:00 PM & 8.36 & 8.36 & 8.74 & 8.20 & 8.33 & Surut \\
\hline
\end{tabular}

\subsection{Evaluasi Tata Air Eksisting}

Bentuk jaringan sistem tata air eksisting pada Daerah Rawa Unit Tamban adalah sistem anjir yang menghubungkan Sungai Barito dengan Sungai Kapuas Murung. Daerah yang berada di kiri dan kanan anjir diairi dengan membangun handil/parit tegak lurus kanal. Pada tahun 2013 dilakukan rehabilitasi dengan membangun pintu klep dengan maksud memisahkan antara saluran pengairan (saluran pembawa/ saluran suplai) dengan saluran pengatusan (saluran pembuang/saluran drainase) dan mengarahkan aliran pada satu jalan (one way flow system). Sehingga pintu tersebut, berfungsi hanya sebagai penyuplai air pada saat kondisi muka air pasang.

Kondisi di lapangan, petani tidak memfungsikan pintu tersebut sesuai dengan rencana awal. Pintu air dibiarkan terbuka, hal ini dimaksudkan Petani agar air dapat dengan mudah terbuang pada saat air pasang. Petani berasumsi bahwa elevasi dasar pintu terlalu tinggi, adanya pintu air tersebut dirasa menyulitkan petani untuk mendrain kelebihan air di sawah. Akibatnya pintu-pintu air yang dibangun di saluran tersier saat ini pengoperasiannya tidak difungsikan petani sebagaimana mestinya, sehingga arah aliran yang seharusnya satu arah menjadi dua arah.

\subsection{Simulasi Hec-Ras}

Simulasi Hec-Ras dimaksudkan untuk mempelajari pola aliran yang terjadi di Daerah Rawa Unit Tamban, khususnya di Saluran Sekunder Tamban Sari Bangun. Dalam penelitian ini pemodelan Hec-Ras dilakukan dengan beberapa simulasi. Simulasi dilakukan dengan beberapa kondisi, yaitu kondisi eksisting, kondisi menaikkan elevasi pintu air, kondisi menaikkan elevasi muka air awal di sawah, kondisi menaikkan hidrograf pasang surut. Ringkasan hasil simulasi dari berbagai macam kondisi dapat dilihat pada Tabel 7. Dari tabel tersebut dapat diketahui bahwa pemenuhan kebutuhan air di sawah 1 (hulu) tidak dapat tercukupi pada seluruh kondisi yang telah disimulasi. Hal ini dikarenakan elevasi pasang surut yang terjadi tidak dapat mengairi kebutuhan air baik pada saat masa tanam dalam tahap pengolahan lahan maupun pada saat pertumbuhan tanam. Kondisi paling optimal dalam pemenuhan kebutuhan air di sawah 1 (hulu) adalah pada kondisi simulasi 11, yaitu kondisi di mana hidrograf pasang surut dinaikkan 1,04 kali. Pemenuhan kebutuhan air di sawah 2 (hilir) dapat tercukupi pada kondisi simulasi 10 dan 11, yaitu kondisi dimana hidrograf pasang surut dinaikkan 1,03 kali dan 1,04 kali. Kondisi ini dapat terpenuhi jika kondisi pasang surut di lokasi penelitian lebih tinggi dari hasil pengamatan yaitu sebesar 1,03 kali dan atau 1,04 kali. 
Tabel 7. Rekapitulasi Hasil Simulasi

\begin{tabular}{|c|c|c|c|c|c|c|c|c|c|c|}
\hline \multirow[b]{2}{*}{ Simulasi } & \multicolumn{5}{|c|}{ Titik 1 (sawah hulu) } & \multicolumn{5}{|c|}{ Titik 2 (sawah hilir) } \\
\hline & $\begin{array}{l}\text { Elv. } \\
\text { Muka air } \\
\text { max di } \\
\text { saluran }\end{array}$ & $\begin{array}{c}\text { Elv. } \\
\text { Muka } \\
\text { air max } \\
\text { di } \\
\text { sawah } \\
\end{array}$ & $\begin{array}{c}\text { Volume } \\
\text { air di } \\
\text { sawah }\end{array}$ & $\begin{array}{l}\text { Kebutuhan } \\
\text { air saat } \\
\text { pengolahan } \\
\text { lahan }\end{array}$ & $\begin{array}{l}\text { Kebutuhan } \\
\text { air saat } \\
\text { pertumbuhan } \\
\text { tanaman }\end{array}$ & $\begin{array}{l}\text { Elv. } \\
\text { Muka air } \\
\text { max di } \\
\text { saluran }\end{array}$ & $\begin{array}{l}\text { Elv. } \\
\text { Muka air } \\
\text { max di } \\
\text { sawah }\end{array}$ & $\begin{array}{c}\text { Volume } \\
\text { air di } \\
\text { sawah }\end{array}$ & $\begin{array}{c}\text { Kebutuhan } \\
\text { air saat } \\
\text { pengolahan } \\
\text { lahan }\end{array}$ & $\begin{array}{l}\text { Kebutuhan } \\
\text { air saat } \\
\text { pertumbuhan } \\
\text { tanaman }\end{array}$ \\
\hline & +8.900 & +8.880 & $-1,170$ & -0.16 & -0.18 & +8.890 & +8.880 & $-1,170$ & 0.07 & 0.05 \\
\hline 2 & +8.900 & +8.870 & -100 & -0.17 & -0.19 & +8.890 & +8.700 & 8,650 & -0.11 & -0.13 \\
\hline 3 & +8.900 & +8.700 & 0 & -0.34 & -0.36 & +8.890 & +8.690 & 6,920 & -0.12 & -0.14 \\
\hline 4 & +8.900 & +8.700 & 0 & -0.34 & -0.36 & +8.890 & +8.660 & 1,230 & -0.15 & -0.17 \\
\hline 5 & +8.900 & +8.880 & $-1,140$ & -0.16 & -0.18 & +8.890 & +8.700 & 1,300 & -0.11 & -0.13 \\
\hline 6 & +8.900 & +8.900 & $-6,560$ & -0.14 & -0.16 & +8.890 & +8.800 & $-16,630$ & -0.01 & -0.03 \\
\hline 7 & +8.900 & +9.000 & $-26,460$ & -0.04 & -0.06 & +8.890 & +8.900 & $-33,100$ & 0.09 & 0.07 \\
\hline 8 & +8.900 & +8.800 & -120 & -0.24 & -0.26 & +8.890 & +8.720 & 2,380 & -0.09 & -0.11 \\
\hline 9 & +8.900 & +8.900 & $-5,530$ & -0.14 & -0.16 & +8.890 & +8.720 & $-11,490$ & -0.09 & -0.11 \\
\hline 10 & +9.160 & +8.940 & 12,750 & -0.10 & -0.12 & +9.160 & +8.860 & 37,450 & 0.05 & 0.03 \\
\hline 11 & +9.250 & +8.990 & 22,940 & -0.05 & -0.07 & +9.250 & +8.980 & 37,450 & 0.17 & 0.15 \\
\hline
\end{tabular}

\section{KESIMPULAN}

Kesimpulan dari hasil penelitian ini adalah sebagai berikut:

1. Berdasarkan hasil perhitungan kebutuhan irigasi, diketahui bahwa elevasi muka air yang diperlukan pada sawah 1 (hulu) untuk pengolahan tanah tertinggi di bulan Juni setengah minggu pertama (Juni I) yaitu pada $+9,040 \mathrm{~m}$ dan untuk masa pertumbuhan di bulan Agustus setengah bulan pertama (Agustus I) yaitu pada +9.060 m. Sedangkan untuk sawah 2 (hilir) untuk pengolahan tanah tertinggi di bulan Juni setengah minggu pertama (Juni I) yaitu pada $+8,810 \mathrm{~m}$ dan untuk masa pertumbuhan di bulan Agustus setengah bulan pertama (Agustus I) yaitu pada $+8.830 \mathrm{~m}$.

2. Elevasi muka air tertinggi di Saluran Sekunder Tamban Sari Bangun dari hasil simulasi Hec Ras pada kondisi eksisiting dengan data pengukuran lapangan adalah setinggi $+8,90 \mathrm{~m}$, pada kondisi hidrograf pasang surut di naikkan 1,03 kali adalah setinggi +9,16 m, dan pada kondisi hidrograf pasang surut di naikkan 1,04 kali adalah setinggi $+9,25 \mathrm{~m}$.

3. Berdasarkan hasil simulasi dari berbagai macam kondisi diketahui bahwa pemenuhan kebutuhan air di sawah 1 (hulu) tidak dapat tercukupi pada seluruh kondisi yang telah disimulasi, hal ini dikarenakan elevasi dasar sawah terlalu tinggi, sehingga pasang yang terjadi tidak dapat memenuhi elevasi muka air yang diperlukan.

4. Pemenuhan kebutuhan air di sawah 2 (hilir) dapat tercukupi pada kondisi simulasi 10 , yaitu kondisi dimana posisi pintu air pada elevasi eksisting, pintu air dibuka penuh, dan hidrograf pasang surut dinaikkan 1,03 kali. Kebutuhan air di petak sawah 2 (hilir) dapat terpenuhi jika kondisi pasang surut di lokasi penelitian lebih tinggi dari hasil pengukuran di lapangan yaitu sebesar 1,03 kali dan atau 1,04 kali.

\section{DAFTAR RUJUKAN}

Anggrahini. 1997. Hidrolika Saluran Terbuka. CV. Citra Media: Surabaya.

Chow, Ven Te. 1992. Applied Hydrology. McGrawHill Book Co.: Singapore.

Chow, Ven Te. 1992. Hidrolika Saluran Terbuka (Open Channel Hydraulics). Penerbit Erlangga: Jakarta. 
Fahmi Firmansyah. dkk. 2014. Studi Perencanaan jaringan Tata Air di Daerah Rawa Desa Batanjung Kecamatan Kapuas Kuala Kabupaten Kapuas Propinsi Kalimantan Tengah. Jurnal Universitas Brawijaya Malang: Malang.

Harto, Sri. 1993. Analisis Hidrologi, PT. Gramedia Pustaka Utama, Jakarta.

Hydrologic Engineering Center, 2010, HEC-RAS River Analysis System, Hydraulic Reference Manual, Version 4.1, January 2010, U.S. Army Cormps of Engineers, Davis, CA

Istiarto. 2012. Simulasi Aliran 1-Dimensi Dengan Bantuan Paket Program Hidrodinamika HEC-RAS. Di dalam Modul Pelatihan: Jogjakarta.
Riduan, Rony. 2016. Evaluasi Pola Pergerakan Arus Pada Saluran Reklamasi Pasang Surut Terantang. Jurnal Universitas Lambung Mangkurat: Banjarmasin.

Soemarto, SD. 1987. Hidrologi Teknik. Usaha Nasional: Surabaya.

Suripin. 2003. Sistem Drainase Perkotaan yang Berkelanjutan. ANDI: Yogyakarta.

Triatmodjo, Bambang. 2008. Hidrologi Terapan. Beta Offset: Yogyakarta. 